\title{
The decision on the embryo to transfer after Preimplantation Genetic Diagnosis for $X$-autosome reciprocal translocation in male carrier
}

Sandrine Chamayou*, Maria Sicali, Debora Lombardo, Carmelita Alecci and Antonino Guglielmino

\begin{abstract}
Background: The aim of Preimplantation Genetic Diagnosis (PGD) on embryos produced in vitro is to identify the embryos without genetic or chromosomal defect from those embryos that will develop the genetic disease or are chromosomally abnormal. In case of PGD for structural chromosome indication (PGR-SR), the normal/balanced embryos are transferred in the maternal uterus. This protocol is valid and widely applied for autosomal chromosome translocation. But which embryo should be transferred after preimplantation genetic diagnosis (PGDSR) for $\mathrm{X}$-3 reciprocal translocation in male patient?
\end{abstract}

Case presentation: The female patient was 26 years old with normal 46,XX karyotype. The male patient had a karyotype with balanced translocation 46,Y,t(X;3)(p11.2;p14)mat, inherited from the mother. The female patient underwent two cycles of ovarian stimulation. In the first cycle, the metaphase II oocytes were vitrified, while in the second cycle they were used as fresh. ICSI was performed on vitrified/warmed and fresh oocytes. Embryos were biopsied at blastocyst stage. Chromosomal analysis was performed by Next Generation Sequencing. Eleven blastocysts were biopsied from 23 vitrified/warmed and fresh metaphase II oocytes. Two embryos were diagnosed 46,XY; two embryos were diagnosed 46,XX; four embryos were diagnosed with unbalanced translocations and three embryos were diagnosed aneuploid. We knew that the two embryos diagnosed as $46, X X$ inherited the balanced translocation from the father and the two embryos diagnosed as $46, \mathrm{XY}$ had a normal karyotype. It was explain to the couple that the phenotype of balanced translocated female embryos cannot be predicted because of the random inactivation of $X$ chromosome and that could also occur on the $\operatorname{der}(X)$. The couple asked to have a $46, X Y$ embryo transferred. Clinical pregnancy was obtained and non invasive prenatal test confirmed PGD-SR result.

Conclusions: Proposing PGD-SR for gonosome-autosome reciprocal translocation implies the risk to exclude balanced translocated female embryos with a normal phenotype for transfer because the early and late normal development at post-natal stage cannot be predicted based on the only chromosomal analysis.

Keywords: Genetic counseling, Preimplantation genetic diagnosis, Reciprocal translocation, X-autosome Translocation, $\mathrm{X}$ inactivation

* Correspondence: s.chamayou@yahoo.fr

Unità di Medicina della Riproduzione - Centro HERA, via Barriera del Bosco n

51/53 95030 Sant Agata Li Battiati, Catania, Italy

(c) The Author(s). 2018 Open Access This article is distributed under the terms of the Creative Commons Attribution 4.0 International License (http://creativecommons.org/licenses/by/4.0/), which permits unrestricted use, distribution, and reproduction in any medium, provided you give appropriate credit to the original author(s) and the source, provide a link to the Creative Commons license, and indicate if changes were made. The Creative Commons Public Domain Dedication waiver (http://creativecommons.org/publicdomain/zero/1.0/) applies to the data made available in this article, unless otherwise stated. 


\section{Background}

The primary aim of genetic/chromosomal investigation on embryos produced in vitro is to identify the embryos without genetic/chromosomal defect from those embryos that will develop the genetic disease or are chromosomally unbalanced. The embryos without genetic disease or chromosomally balanced are chosen for embryo-transfer. Preimplantation genetic diagnosis (PGD) is applied in couples with a high risk of inherited defect on offspring such as chromosomal rearrangements including balanced translocations, inversions or deletions [1]. In balanced (Robertsonian or reciprocal) translocations, the carrier parent contains the correct amount of genetic material. If the translocations did not occur within a gene, there is no consequence on carrier phenotype. Nevertheless, the translocated patient has an increased risk for chromosomally unbalanced gametes and conceptions. In case of PGD for structural chromosomal indication (PGD-SR), the embryo diagnosed as diploid for the two entire chromosomes involved in the translocation is chosen for transfer. With the use of the last advanced molecular technologies such as Comparative Genome Hybridization array [2], Single Nucleotide Polymorphism arrays with full molecular karyotyping [3, 4], and Next Generation Sequencing (NGS) [5, 6], a comprehensive chromosomal screening can be performed with a resolution inferior to $1 \mathrm{Mb}[7,8]$. In routine protocols, these methods do not distinguish an embryo with a normal from an embryo with a balanced translocated karyotype. They remain quantitative on the opposite to banding karyotype.

Among chromosomal translocations, reciprocal translocations that are the product of material exchange between two non-homologous chromosomes are reported with an incidence about 1 in 625 newborns [9]. In particular, balanced gonosome-autosome translocations are very rare, with an incidence estimated in about $1 / 30,000$ live births [10]. Actually, the only available databases that we are aware of on PGD are those from the ESHRE PGD Consortium. On 5247 PGD-SR, only 42 cases due to female or male indications were recorded [11]. In particular, there were listed 16 cases for X-autosome translocation with female indication, 24 cases for Y-autosome translocation with male indication and only 2 cases for $\mathrm{X}$-autosome translocation with male indication [12].

In 1962, Mary Lyon established that one X-chromosome is randomly inactivated in woman to equilibrate the $\mathrm{X}$-linked gene expression between the two sexes [13]. In women with a balanced $\mathrm{X}$-autosome translocation, the normal $\mathrm{X}$ chromosome is preferentially inactivated [14] and a normal phenotype is expressed. Nevertheless, the choice of the $\mathrm{X}$ chromosome to inactivate is random and can occur on the $\operatorname{der}(\mathrm{X})$. In this case, the gene silencing is spread into the autosomal attached segment leading to female patients with genetic disorders with variable gravity.
We presently describe a case of PGD-SR for reciprocal X-3 (p11.2;p14) translocation in male patient. Normal male and balanced translocated female embryos were obtained. We discuss the dilemma of choosing of the embryo to transfer according to sex, in those embryos with unpredictable phenotype. The present work is the first published case of PGD-SR for gonosome-autosome translocation with male indication.

\section{Case presentation \\ Material and methods \\ Patients}

The female patient was 26 years old at the time of PGD-SR. Karyotype was 46,XX. Basal FSH, LH on day 3 and $A M H$ value were respectively $8.0 \mathrm{IU} / 1,6.5$ IU/l and $6.3 \mathrm{ng} / \mathrm{ml}$. She had a 30 days ovarian cycle. Uterine cavity and fallopian tubes resulted regular from diagnostic examination. The ovaries had a polycystic ovarian aspect. The patient had no previous pregnancy.

The male patient was 30 years old at the time of PGD-SR. After QFQ-banding karyotype analysis, he was found to have a karyotype with balanced translocation involving $\mathrm{X}$ chromosome and autosome 3: 46,Y,t(X;3)(p11.2;p14)mat (Fig. 1).

The X-3 reciprocal translocation was transmitted from the mother that had the karyotype 46,X,t(X;3)(p11.2;p14) in the blood cells. In the family of male patient, the first sibling had a 46,XX normal karyotype (II-1). The third of three siblings (II-5) showed the same karyotype $46, \mathrm{Y}, \mathrm{t}(\mathrm{X} ; 3)(\mathrm{p} 11.2 ; \mathrm{p} 14)$ mat of the patient. The parents of the patient were not consanguineous (Fig. 2). His mother and siblings had a normal phenotype.

The male patient had a normal phenotype with normal genital tract.

Semen was characterized by severe oligoasthenoteratozoospermia (Semen concentration: 20.000 sperm /ml; 5\% sperm with progressive motility, $2 \%$ of normal sperm). From blood cells analysis, the male patient resulted negative for microdeletions of AZFa, AZFb and AZFc regions [15]. The male endocrine was normal for FSH, LH, total Testosterone, Free Testosterone, 17bE2, Prolactin, HCG, aFP. The couple consulted for the first time an infertility center for primary infertility and asked to know 'the state of health' of the embryos as allowed by the Italian law on Medically Assisted Procreation [16].

The following protocols of ovarian stimulation, oocyte and embryo vitrification, ICSI and embryos culture, embryo biopsy and NGS have been described elsewhere and are resumed as follow [17]. Each part of the protocol has been approved by the Institutional Review Board Unità di Medicina della Riproduzione - Centro HERA. The patients signed informed consent forms on all procedures prior application. 


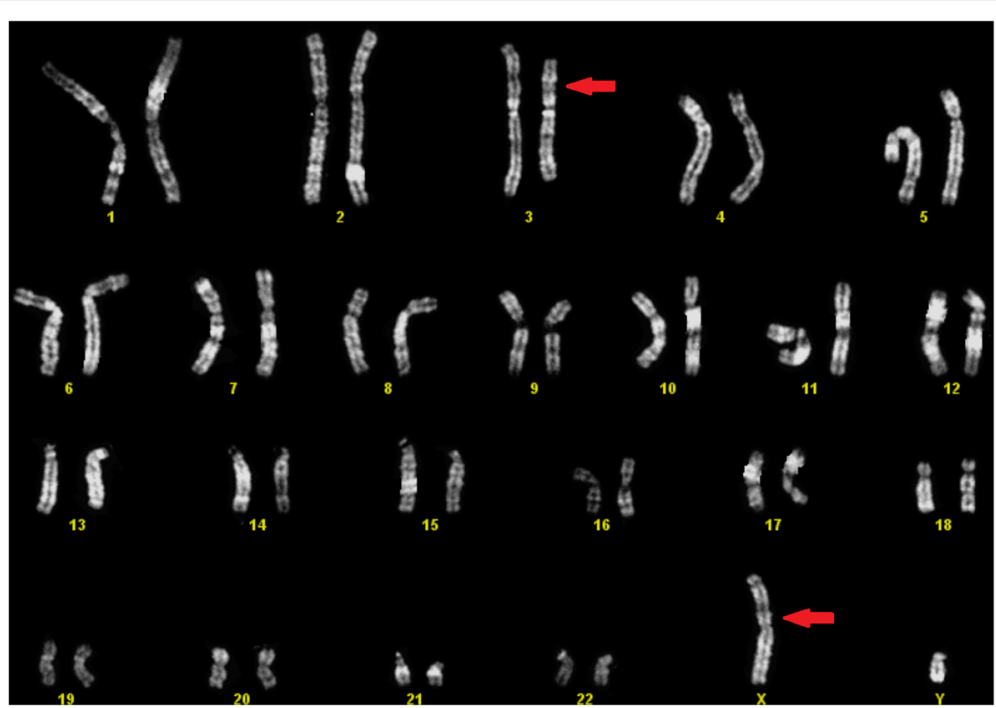

Fig. 1 Karyotype 46,Y,t(X,3)(p11.2;p14)mat of male patient

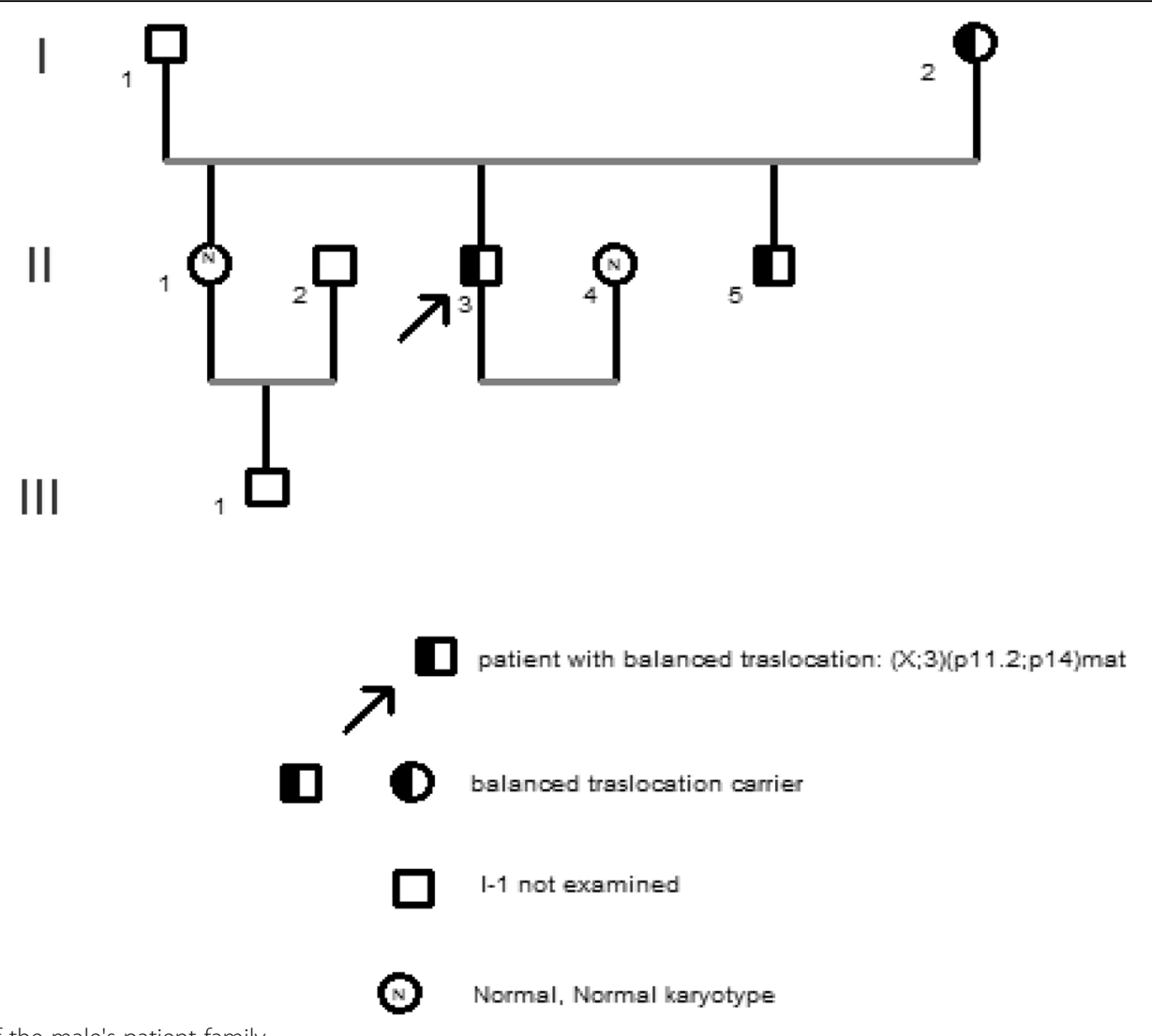

Fig. 2 Pedigree of the male's patient family 


\section{Ovarian stimulation}

The female patient underwent two cycles of ovarian stimulation. In the first cycle, the metaphase II oocytes were vitrified. In the second cycle the metaphase II oocytes were used as fresh together with the previously vitrified/warmed oocytes.

The first ovarian stimulation was performed by the administration of recombinant FSH and LH (Puregon, MSD, Franklin Lakes, USA and Luveris: Merck-Serono, London, UK) from cycle day 2 in a luteal gonadotrophin-releasing hormone antagonist flexible schema (Orgalutran : MDS). Initial doses were $200 \mathrm{IU} /$ day for FSH and $75 \mathrm{IU} /$ day for LH. Luteal gonadotrophin-releasing hormone antagonist was given when the leader follicle reached $14 \mathrm{~mm}$ in diameter with a dosage of $0.25 \mathrm{mg} /$ day. The second ovarian stimulation started on day 2 of the following cycle.

One ICSI session was performed using the accumulated vitrified/warmed oocytes together with the lately produced fresh oocytes and fresh male patient semen.

ICSI on vitrified/warmed and fresh oocytes and embryo culture Vaginal ultrasound-guided aspiration of oocyte-cumulus complex (OPU) was performed 35 hours after human chorionic gonadotrophin administration (HCG 10,000 IU, Gonasi: AMSA, Rome, Italy). ICSI was performed on fresh oocytes $3 \mathrm{~h}$ after OPU and on cryopreserved oocytes 1 hour after warming and in vitro culture with the same patient's fresh ejaculated spermatozoa sample.

After ICSI, in vitro culture was carried out in Continuous single culture complete medium with human serum albumin (Irvine Scientific, Santa Ana, USA) under mineral oil and in automated incubators with 5\% CO2, 5\% $\mathrm{O} 2$ at $37^{\circ} \mathrm{C}$, fitted with time-lapse imaging acquisition (Embryoscope, Unisense, Aarhus, Denmark).

\section{Embryo biopsy}

Embryo biopsies were performed on day 5 on expanded or hatching blastocysts. Few trophectoderm cells [5 to 10] were removed from a zona pellucida hole using a $1.48 \mathrm{um}$ diode laser (OCTAX, Bruckberg, Germany) and a $20 \mathrm{um}$ inner diameter biopsy pipette. After the biopsy procedure, each embryo was incubated until embryo vitrification and before blastocyst re-expension. The biopsied trophectoderm cells were washed in sterile phosphate buffered saline (PBS) solution and transferred into a $0.2 \mathrm{ml}$ Eppendorf tube containing $4 \mathrm{ul}$ of sterile PBS solution.

\section{Oocyte/embryo vitrification and warming}

The vitrification and warming protocols for oocyte [18] and embryos [19] were previously described.

\section{Cell lysis, whole genome amplification and NGS protocol}

The biopsied trophectoderm cells were submitted to alkaline lyses and whole genome amplification according to
Repli-g Single Cell protocol (Qiagen, Hilden, Germany). After quantification of amplified DNA, libraries were prepared from $100 \mathrm{ng}$ of each sample and barcoded with IonXpressPlus Fragment and IonXpress Barcode Adapter kits (Life Technologies-Thermo Fisher (Carlsbad, USA). After quantification of the libraries, normalization to 100 $\mathrm{pM}$ and mix-up to obtain a final concentration of $8 \mathrm{pM}$, the eleven enriched libraries were loaded on Chip 16 V2. DNA sequencing was performed on ION PGM HiQ View Sequencing in Ion Personal Genome Machine. The updated Torrent Suite Software was used for base calling and mapping on human genome reference sequence Hg19. For each chromosome read coverage was corrected by guanine-cytosine calculation. Aneuploidy was diagnosed comparing data to baseline values multiple male samples. In all the process, a positive control with normal male DNA and a negative control from biopsy culture media were processed together with the samples to diagnose. Genetic analysis was validated when median absolute pair wise difference (MAPD) was inferior to 0.3. Chromosomal segments as short as $7 \mathrm{Mb}$ could be detected. The protocol was previously validated on single cells from amniocytes with different karyotypes [17].

\section{Endometrial preparation for embryo transfer}

Warming and single embryo transfer was performed on natural cycle at 7 days after LH surge.

\section{Results}

\section{In vitro results}

The results of oocyte vitrification, ICSI, embryo culture and embryo biopsy analysis from vitrified/warmed and fresh oocytes are presented in Table 1.

The patient produced 8 metaphase II oocytes that were vitrified during the first ovarian cycles and 16 metaphase II oocytes in the second ovarian cycle that were used as fresh. Seven of the 8 vitrified oocytes survived to warming and were micro-injected together with the 16 fresh oocytes with the male patient' semen sample and in the same ICSI procedure. The fertilization rates were $71.4 \%$ for vitrified/warmed oocytes (5 zygotes/7 micro-injected oocytes) and $75.0 \%$ for fresh oocytes (12 zygotes/16 micro-injected oocytes). On day V, 3 expanded or hatching blastocysts from vitrified/warmed oocytes (3 blastocysts/5 zygotes, $60.0 \%$ ) and 8 expanded or hatching blastocysts from fresh oocytes (8 blastocysts/12 zygotes, 67.0\%) were biopsied and vitrified.

\section{Genetic results}

The genetic analysis were validated and completed respectively in $100 \%$ of the biopsied blastocysts from vitrified/warmed and fresh oocytes. Chromosome contents of each blastocyst after PGD-SR are reported in Table 2. 
Table 1 in vitro results of PGD-SR treatment

\begin{tabular}{lll}
\hline & $\begin{array}{l}\text { Vitrified/ } \\
\text { warmed } \\
\text { oocytes } \\
\text { (1st ovarian } \\
\text { stimulation) }\end{array}$ & $\begin{array}{l}\text { Fresh oocytes } \\
\text { (2nd ovarian } \\
\text { stimulation) }\end{array}$ \\
\hline Metaphase II oocytes at OPU & 8 & 16 \\
Vitrified oocytes & 8 & - \\
Survived oocytes & 7 & - \\
Micro-injected oocytes & 7 & 16 \\
Zygotes (fertilization rate) & $5(71.4)$ & $12(75.0)$ \\
Expanded/hatching biopsied & $3(60.0)$ & $8(67.0)$ \\
Blastocysts (proportion on zygote) & & 8 \\
Vitrified biopsied blastocysts & 3 & \\
\hline
\end{tabular}

According to the karyograms generated by IGV (Integrative Genomics Viewer), it was found that two embryos were diagnosed 46,XY, two embryos were diagnosed 46,XX; four embryos were diagnosed with unbalanced translocations and showed the trisomy 3 p14 $\rightarrow$ cen $\rightarrow$ 3qter and monosomy Xp11.2 $\rightarrow$ cen $\rightarrow$ Xqter, from 2:2 segregation and adjacent-2 disjunction. Three embryos were diagnosed aneuploid (45,X0 ; 45,XY,del [2] ;46,XY,del [8](qter $\rightarrow$ q22.1). Even if balanced translocation could be detected by NGS analysis, the 2 embryos diagnosed as $46, \mathrm{XX}$ were known to have the balanced translocation inherited by the father and their true karyotype was: 46,X,t(X;3)(Xqter $\rightarrow \mathrm{Xp} 11.2:: 3 \mathrm{p} 14 \rightarrow$ 3 pter;3qter $\rightarrow 3 p 14:: X p 11.2 \rightarrow X p t e r)$ pat. On the same way, the 2 embryos diagnosed as 46,XY had a normal karyotype. Karyograms are shown in Fig. 3.

\section{Genetic counseling}

Prior to PGT-SR, a genetic counselling was performed and the couple was informed on the possible karyotypes due to father reciprocal translocation: embryo(s) with normal 46,XY, female(s) with balanced translocation and unpredictable phenotype, embryo(s) with unpredictable complete or partial aneuploidies.

After PGT-SR, the patients were informed on the result of the present PGD-SR. It was explained that among the viable embryos, the 2 male embryos had the true kayotype 46,XY, 2 female embryos had the reciprocal translocation $\quad 46, \mathrm{X}, \mathrm{t}(\mathrm{X} ; 3)(\mathrm{Xqter} \rightarrow \mathrm{Xp} 11.2:: 3 \mathrm{p} 14 \rightarrow 3$ pter; 3qter $\rightarrow 3$ p14::Xp11.2 $\rightarrow$ Xpter)pat.

Regarding the 2 female embryos with balanced translocation, it was explained that the phenotype should be normal, due to the preferable silencing of normal $\mathrm{X}$ as it seems to have happened in the patient's mother. Consequently, deciding not to transfer balanced translocated female means taking the risk of eliminating from transfer and pregnancy a viable embryo with a normal phenotype.

On the other side, genetic disorders with different degree of gravity (from gonadal digenesis and premature ovarian failure to major genetic disorders and mental retardation) were reported in female patients with balanced reciprocal $\mathrm{X}$-autosome translocations. This risk exists and remains unpredictable. The probability of occurring cannot be calculated.

Finally, one embryo had 45,X0 karyotype. It was explained that Turner Syndrome has a large expressivity [20] and a very high in uterus lethality within the first trimester of pregnancy $[21,22]$.

It was reminded that de novo balanced translocation could not be detected by the present protocol of NGS.

After counselling, the couple asked to have one 46,XY embryo thawed and transferred.

\section{Clinical outcome}

The embryo $n .13$ obtained from fresh oocyte, was thawed and transferred. The $\beta$-HCG test performed 12 days after embryo transfer was positive. Two weeks later the clinical pregnancy was ascertained by scan of embryonic sac and

Table 2 Chromosome content of blastocyst after PGD-SR

\begin{tabular}{|c|c|c|c|c|c|}
\hline Embryo n. & Oocyte origin & Chromosome content & n. Reads & Coverage & MAPD \\
\hline 1 & Fresh & 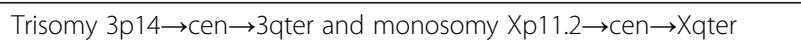 & 130,326 & $99.90 \%$ & 0.170 \\
\hline 3 & Fresh & $46, X Y$ & 106,478 & $99.91 \%$ & 0.217 \\
\hline 4 & Fresh & Trisomy 3 p $14 \rightarrow$ cen $\rightarrow 3$ qter and monosomy $\mathrm{Xp} 11.2 \rightarrow$ cen $\rightarrow$ Xqter & 278,023 & $99.78 \%$ & 0.176 \\
\hline 6 & Fresh & Trisomy 3 p $14 \rightarrow$ cen $\rightarrow 3$ qter and monosomy $\mathrm{Xp} 11.2 \rightarrow$ cen $\rightarrow$ Xqter & 90,688 & $99.92 \%$ & 0.226 \\
\hline 12 & Fresh & $46, X, t(X ; 3)(X q t e r \rightarrow X p 11.2: 3 p 14 \rightarrow 3$ pter;3qter $\rightarrow 3 p 14:: X p 11.2 \rightarrow$ Xpter)pat & 70,759 & $99.95 \%$ & 0.226 \\
\hline 13 & Fresh & $46, X Y$ & 124,119 & $99.90 \%$ & 0.203 \\
\hline 14 & Fresh & $45, \times 0$ & 125,875 & $99.90 \%$ & 0.198 \\
\hline 16 & Fresh & $45, X Y$,del [2] & 412,006 & $99.66 \%$ & 0.153 \\
\hline 17 & Vitrified/warmed & $46, X Y$,del [8](qter $\rightarrow q 22.1)$ & 157,459 & $99.87 \%$ & 0.176 \\
\hline 18 & Vitrified/warmed & Trisomy 3 p $14 \rightarrow$ cen $\rightarrow 3$ qter and monosomy $\mathrm{Xp} 11.2 \rightarrow$ cen $\rightarrow$ Xqter & 118,589 & $99.90 \%$ & 0.200 \\
\hline 22 & Vitrified/warmed & $46, X, t(X ; 3)(X q$ ter $\rightarrow$ Xp11.2::3p14 $\rightarrow 3$ pter;3qter $\rightarrow 3 p 14:: X p 11.2 \rightarrow$ Xpter)pat & 133,527 & $99.89 \%$ & 0.179 \\
\hline
\end{tabular}




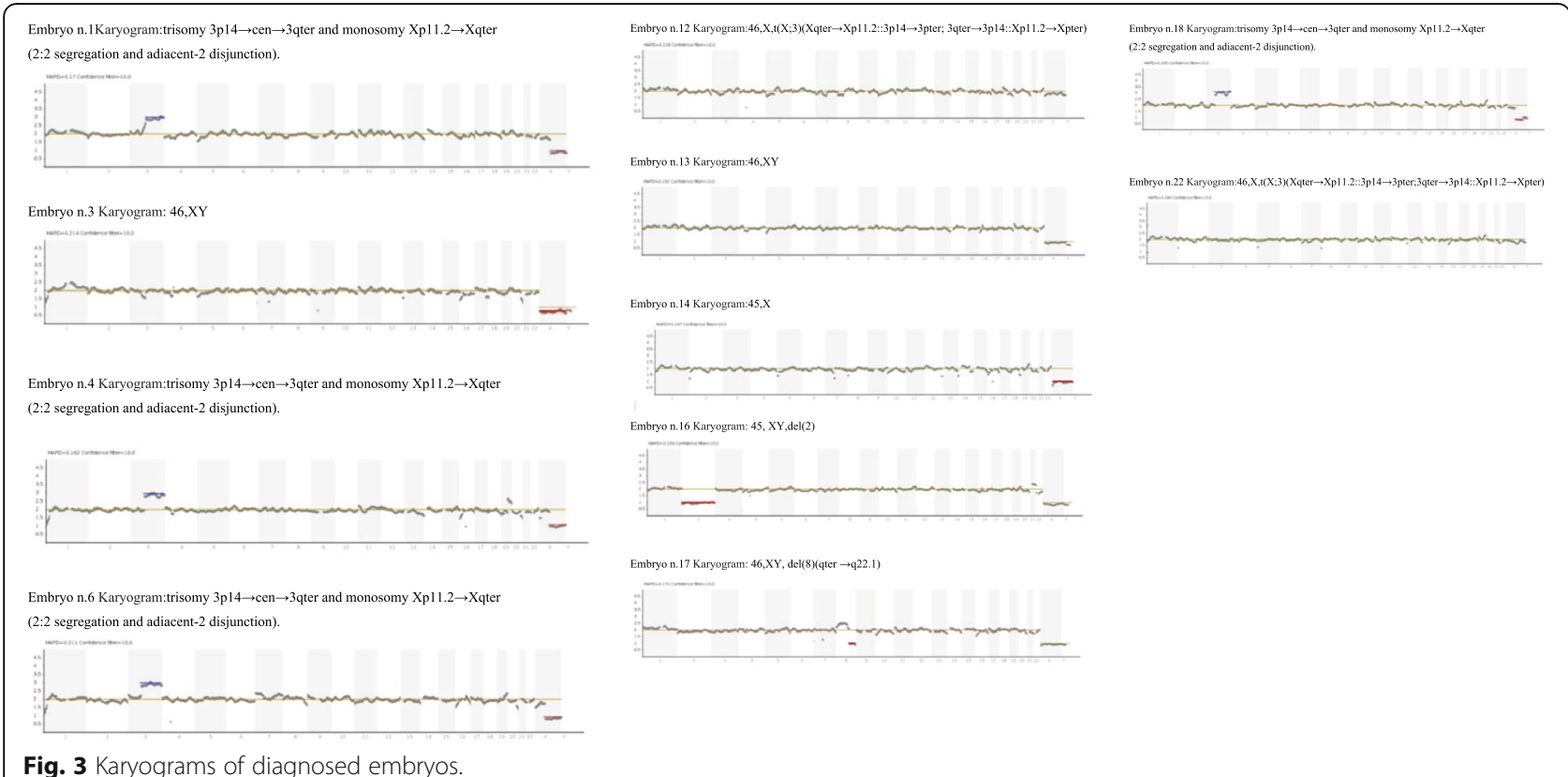

Fig. 3 Karyograms of diagnosed embryos.

one foetal heart beat was observed. Non invasive prenatal testing (NIPT) for all autosome and gonosome chromosomes was performed on the 15th week of pregnancy and confirmed PGD-SR result.

\section{Discussion and conclusions}

We reported a rare case of PGD-SR for reciprocal X-3 translocation in male patient. The couple came for primary infertility and the male patient discovered to have the karyotype 46,XY,t(X;3)(p11.2;p14)mat in diagnostic phase. The reciprocal translocation was inherited from his mother that had a normal phenotype. The male patient had a severe oligoasthenoteratozoospermia probably due to the structural chromosome abnormality [23]. ICSI was proposed to address the male infertility due to sperm parameters alteration and the couple asked to know 'the state of health of their embryos' as allowed by the Italian law [16]. Consequently, PGD-SR protocol for complete and partial aneuploidie for all chromosomes was applied. On the 11 embryos obtained after two ovarian stimulations and from vitrified/warmed and fresh oocytes, four embryos $(36,4 \%)$ were diagnosed with a normal karyotype after NGS analysis, two 46,XY and two 46,XX embryos. Even if it was not possible to detect it by NGS, we knew that the two 46,XY embryos had a normal karyotype (excepted if de novo balanced translocations occurred), and the two 46,XX embryos carried the reciprocal translocation inherited from the father and were $46, \mathrm{X}, \mathrm{t}(\mathrm{X} ; 3)(\mathrm{Xqter} \rightarrow \mathrm{Xp11.2::3p14 \rightarrow 3pter;3qter}$ $\rightarrow 3$ p14::Xp11.2 $\rightarrow$ Xpter)pat.

In 2016, Ferfouri et al. presented two cases in which the female patient carried a balanced reciprocal translocation X-autosome [24]. After embryo biopsy on day 3 and FISH analysis, 2/30 (6.7\%) embryos resulted normal/balanced. No live birth was obtained after the embryo transfer of two balanced female embryos. In the present case, 4/11 (36.4\%) were analysed as chromosomally balanced after embryo biopsy at blastocyst stage.

Among the gonosome-autosome translocations, the $\mathrm{X}$-autosome reciprocal translocations are known to be the most sensitive cases because the phenotype can vary in female carriers. In these cases the normal X chromosome is preferentially inactivated forming the Barr body [25] and the phenotype is normal. Nevertheless, the phenomenon of $\mathrm{X}$ inactivation controlled by the $\mathrm{X}$-inactivation centre (XIC) located in Xq13 occurs randomly in one chromosome or the other. In the present case and if lyonisation occurs in the translocated $\mathrm{X}$ chromosome, there will be monosomy of autosomic's segment translocated in $\mathrm{X}$ chromosome happens on the $\operatorname{der}(\mathrm{X}) \mathrm{t}(3 \mathrm{pter} \rightarrow 3 \mathrm{p} 14:: \mathrm{Xp} 11.2 \rightarrow \mathrm{Xpter})$ con-

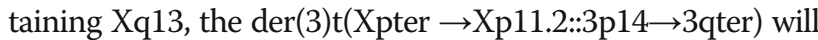
not be silenced. Consequently, there will be a double dosage of genes from the portion (Xpter $\rightarrow$ Xp11.2) and a monosomy of the portion (3pter $\rightarrow 3 \mathrm{p} 14$ ).

It has been previously reported that balanced $\mathrm{X}$-autosome translocated females can express an unpredictable phenotype that can vary from gonadal dygenesis and premature ovarian failure to multiple congenital anomalies and mental retardation [26].

In human the $\mathrm{X}$ inactivation starts on day 3 due to the silencing process of one $\mathrm{X}$ chromosome in female embryos. In the present PGD-SR application, embryo biopsy was performed on day 5 on trophectoderm cells. These cells will generate embryonic annexes and not be 
part of the embryo. No published data has shown that the study of gene silencing in trophectoderm cells would be representative of gene silencing in the balanced translocated female embryo itself. One of the few alternatives to predict the phenotype of female infants could be the study of X-chromosome inactivation/DNA methylation from foetus blood cells, in prenatal phase [27]. But once again, it remains to demonstrate that X-chromosome inactivation from foetus blood cells would be truly representative of overall gene expression in the infant, the girl and the woman [28].

Regarding the request of the couple to know the state of health of their embryos, we could not answer in sensus strictus on the early and late development of the balanced translocated female embryos at post-natal stage as précised during the pre-PGT-SR genetic counselling. At the post-PGT-SR genetic counselling, the couple decided not to consider them as the first choice for embryo transfer. This choice opens an ethical dilemma because, at the same time, embryos with a probably normal phenotype are eliminated from the transfer and possible birth. This would have happened to the male patients' mother at her time! The couple asked to have one 46,XY embryo transferred. They obtained the pregnancy and PGD-SR was confirmed by NIPT.

Among those embryos with abnormal karyotype, there was a 45,X0 embryo with a potential to implant but high probability to miscarriage. The couple rejected its transfer in uterus. There were 6 non-viable embryos left. One embryo with 45,XY,del [2], one embryo with 46,XY,del [8](qter $\rightarrow$ q22.1) and four embryos with trisomy 3p14 $\rightarrow$ cen $\rightarrow 3$ qter and monosomy Xp11.2 $\rightarrow \mathrm{cen} \rightarrow$ Xqter. The last four embryos were the product of fertilization from a normal haploid 23,X oocyte and an unbalanced $23, \operatorname{der}(\mathrm{X}) \mathrm{t}(\mathrm{X} ; 3)$

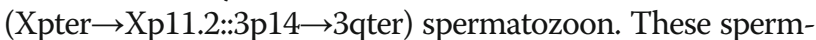
atozoa were the product of adjacent- 2 chromosome segregation of the translocated chromosomes during the first meiotic division. This unbalanced segregation is reported as the most rare in reciprocal translocation [29]. Similar chromosomal abnormalities were observed in embryos from vitrified/warmed (embryos n. 18 and 22) and fresh oocytes (embryos n. 1, 4, 6 and 12). None of the analysed embryos showed mosaicism.

The present case is the first PGD-SR for gonosome-autosome translocation with male indication. Van Echten-Arends et al. previously reported a PGD-SR gonosome-autosome translocation with female indication that resulted in misdiagnosis for technical problem [30]. Comprehensive chromosomal screening by NGS is the method of choice for PGD of structural chromosomal defect.

This present PGD-SR application for reciprocal X-3 translocation in male patient arises the dilemma of balanced embryos excluded for transfer due to their phenotype unpredictability. The present case shows the limits of PGD-SR in helping the couple with a gonosome-autosome translocation to have a healthy child. Other PGD cases are well-known to be unsolvable at preimplantation stage due to the impossibility to predetermine the phenotype and development of the conceptus. Some of them are PGD for rare CFTR mutations and unknown combined phenotype, multifactory disease (heart defects, cancers, diabetes,...), diseases with variable expressivity (Marfan Syndrome, hereditary non-polyposis colorectal cancer,...) and diseases with late onset (ex: Alzheimer's disease). In these cases, proposing PGD implies the elimination of possible normal embryos for transfer.

\section{Abbreviations}

aFP: alpha feto protein; AMH: Anti-Müllerian hormone; AZF: Azoospermic Factor; CFTR: Cystic Fibrosis Transmembrane conductance Regulator; FISH: Fluorescent In Situ hybridization; FSH: Follicle-Stimulating Hormone; HCG: Human chorionic gonadotropin; ICSI: Intra Cytoplasmic Sperm Injection; LH: Luteinizing Hormone; MAPD: Median Absolute Pair wise Difference; NGS: Next Generation Sequencing; NIPT: Non Invasive Prenatal Testing; OPU: Oocyte Pick-UP; PGD: Preimplantation Genetic Diagnosis; PGDSR: Preimplantation Genetic Diagnosis for Structural chromosomal indication

\section{Acknowledgements}

we thank Dr. Uccellatore for scientific contribution in manuscript revision.

Funding

The present study was carried out with no fund.

Availability of data and materials

All data and material are available is if requested.

\section{Authors' contribution}

SC: wrote the manuscript, contributed to NGS analysis, is the director of In Vitro Laboratory and NGS laboratories. MS: contributed to manuscript writing, performed NGS analysis. DL: contributed to manuscript writing, performed caryotypes of the couple. CA: contributed to manuscript writing performed freezing/thawing procedures. AG: contributed to manuscript writing, is the director of Infertility clinic, followed the couple as a clinician. All authors read and approved the final manuscript.

Each part of the protocol has been approved by the Institutional Review Board Unità di Medicina della Riproduzione - Centro HERA. The patients signed informed consent forms on all procedures prior application.

Ethics approval and consent to participate

Each part of the protocol has been approved by the Institutional Review Board Unità di Medicina della Riproduzione - Centro HERA. The patients signed informed consent forms on all procedures prior application.

\section{Consent for publication}

The patients gave their written consent for the publication of their clinical case.

\section{Competing interests}

None of the authors had competing (financial or personal) interest in the application and the publication of the present study. It was just for the pleasure and utility to share science.

\section{Publisher's Note}

Springer Nature remains neutral with regard to jurisdictional claims in published maps and institutional affiliations. 
Received: 9 October 2018 Accepted: 26 November 2018

Published online: 29 December 2018

\section{References}

1. Scriven PN, Handyside AH, Ogilvie C. Chromosome translocations, segregation modes and strategies for preimplantation genetic diagnosis. Prenat Diagn. 1998;18:1437-49.

2. Handyside AH. 24-chromosome copy number analysis: a comparison of available technologies. Fertil.Steril. 2013:100(3):595-602.

3. Handyside AH, Harton GL, Mariani B, Thornhill AR, Affara N, Shaw MA, Griffin DK. Karyomapping: a universal method for genome wide analysis of genetic disease based on mapping crossovers between parental haplotypes. J Med Genet. 2010:47(10):651-8.

4. Johnson DS, Cinnioglu C, Ross R, Filby A, Gemelos G, Hill M, Ryan A, Smotrich D, Rabinowitz M, Murray MJ. Comprehensive analysis of karyotypic mosaicism between trophectoderm and inner cell mass. Mol Hum Reprod. 2010;16(12):944-9.

5. Wells D, Kaur K, Grifo J, Glassner M, Taylor JC, Fragouli E, Munne S. Clinical utilisation of a rapid low-pass whole genome sequencing technique for the diagnosis of aneuploidy in human embryos prior to implantation. J Med Genet. 2014;51(8):553-62.

6. Fiorentino F, Bono S, Biricik A, Nuccitelli A, Cotroneo E, Cottone G, Kokocinski F, Michel CE, Minasi MG, Greco E. Application of next-generation sequencing technology for comprehensive aneuploidy screening of blastocysts in clinical preimplantation genetic screening cycles. Hum. Reprod. 2014:29(12):2802-13.

7. Fan J, Wang L, Wang H, Ma M, Wang S, Liu Z, Xu G, Zhang J, Cram DS, Yao $Y$. Theclinical utility of next-generationsequencing for identifying chromosomedisease syndromes in human embryos. ReprodBioMed Online. 2015:31(1):62-70

8. $\quad$ Ou J, Wang W, Feng T, Liao L, Meng Q, Zou Q, Ding J, Zheng A, Duan C, Li $\mathrm{P}$, Liu Q, Lin C and Li H. Identification of small segmental translocations in patients with repeated implantation failure and recurrent miscarriage using next generationsequencing after in vitro fertilization/intracytoplasmic sperm injection.Mol Cytogenet 2015;8:105, 1-7

9. Van Dyke DL, Weiss L, Roberson JR, Babu VR. The frequency and mutation rate of balanced autosomal rearrangements in man estimated from prenatal genetic studies for advanced maternal age. Am J Hum Genet. 1983;35:301-8.

10. Gupta N, Goel H, Phadke SR. Unbalanced X; Autosome translocation. Indian J Pediatr. 2006:73:840-2.

11. De Rycke M, Goosens V, Kokkali G, Meijer-Hoogeveen M, Coonen E, Moutou C. ESHRE PGD collection XIV-XV: cycles from January 2011 to December 2012 with pregnancy follow-up to October 2013. Hum. Reprod. 2017; 32(10):1974-1994

12. De Rycke M, Belva F, Goossens V, Moutou C, SenGupta SB, TraegerSynodinos J, Coonen E. ESHRE PGD Consortium data collection XIII: cycles from January to December 2010 with pregnancy follow-up to October 2011. Hum. Reprod. 2015;30(8):1763-89.

13. Lyon MF. Sex chromatin and gene action in the mammalian Xchromosome. Am J Hum Genet. 1962:14:135-48.

14. Schmidt M, De Sart D. Functional disomies of the $X$ chromosome influence the cell selection and hence the $X$ inactivation pattern in females with balanced $X$-autosome translocations: a review of 122 cases. Am J Med Genet. 1992;42:161-9.

15. Krausz C, Hoefsloot L, Simoni M, Tuttelmann F. EAA/EMQN best practice guidelines for molecular diagnosis of $\mathrm{Y}$-chromosomal microdeletions; stateof-the-art 2013. Andrology. 2014;2:5-19.

16. Parlamento Italiano. Legge n.40: Norme in materia di procreazione medicalmente assistita. Gazzetta ufficiale. 2004; n.45 del 24 febbraio 2004

17. Chamayou S, Sicali M, Alecci C, Ragolia C, Liprino A, Nibali D, Storaci G, Cardea A, Guglielmino A. The accumulation of vitrified oocytes is a strategy to increase the number of euploid available blastocysts for transfer after preimplantation genetic testing. JAssist Reprod Genet. 2017;34(4):479-86.

18. Chamayou S, Bonaventura G, Alecci C, Tibullo D, Di Raimondo F, Guglielmino A, Barcellona ML. Consequences of metaphase II oocyte cryopreservation on mRNA content. Cryobiology. 2011;62:130-4.

19. Kuwayama M. Highly efficient vitrification for cryopreservation of human oocytes and embryos: the Cryotop method. Theriogenology. 2007:67:73-80.

20. Gravholt $\mathrm{CH}$, Andersen NH, Conway GS, Dekkers OM, Geffner ME, Klein KO, Lin AE, Mauras N, Quigley CA, Rubin K, Sandberg DE, Sas TCJ, Silberbach M, Söderström-Anttila V, Stochholm K. van Alfen-van derVelden JA, Woelfe J,
Backeljauw. Clinical practice guidelines for the care of girls and women with Turner syndrome: proceedings from the 2016 Cincinnati International Turner Syndrome Meeting. Eur J Endocrinol. 2017;177:G1-G70.

21. Hook EB. Chromosome abnormalities and spontaneous fetal death following amniocentesis: further data and associations with maternal age. Am J Hum Genet. 1983;35:110-6.

22. Hardy K, Hardy P, Jacobs PA, Lewallen K, Hassold TJ. Temporal changes in chromosome abnormalities in human spontaneous abortions: results of 40 years of analysis. AmJ Med Genet. 2016;170A:2671-80.

23. Perrin A, Douet-Guilbert N, Le Bris MJ, Keromnes G, Langlois ML, Barrière $P$, Amice J, Amice V, De Braekeleer M, Morel F. Segregation of chromosomes in sperm of a $t(X ; 18)(q 11 ; p 11.1)$ carrier inherited from his mother: case report. Hum Reprod. 2008;23(1):117-30.

24. Ferfouri F, Bernicot I, Schneider A, Pharm D, Haquet E, Hédon B, Anahory T. Is the resulting phenotype of an embryo with balanced $\mathrm{X}$-autosome translocation, obtained by means of preimplantation genetic diagnosis, linked to the X inactivation pattern? Fertil Steril. 2016;105(4):1035-46.

25. Barr ML, Bertram EG. A morphologcical distinction between neurons of the male and female, and the behavior of the nucleolar satellite during accelerated nucleoprotein synthesis. Nature. 1949;163:676.

26. McKinlay Gardner RL, Sutherland GR, Shaffer LG. Chromosome abnormalities and genetic counselling. Eds. Oxford monographs on medical genetics. 2012;N.61

27. Ma S, Ho Yuen B, Penaherrera M, Koehn D, Less L, Robinson W. ICSI and the transmission of $X$-autosomal translocation: a three-generation evaluation of X:20 translocation: Case report. Hum Reprod. 2003;18(7):1377-82.

28. Giorgietti L, Galupa R, Nora EP, Piolot T, Lam F, Dekker J, Tiana G, Heard E. Predictive polymer modeling reveals couples fluctuations in chromosome conformation and transcription. Cell. 2014;157(4):950-63.

29. Jalbert $P$, Sele $B$, Jalbert $H$. Reciprocal translocations: a way to predict the mode of imbalanced segregation by pachytene-diagram drawing. A study of 151 human translocations. Hum Genet. 1980;55:209-22.

30. Van Echten-Arend J, Coonen E, Reuters B, Suijkerbuijk RF, Dul EC, Land JA van Ravenswaaij-Arts CMA. Preimplantation genetic diagnosis for $X_{i}$ autosome translocations: lessons from a case of misdiagnosis. Hum Reprod. 2013;(11):3141-5.

\section{Ready to submit your research? Choose BMC and benefit from:}

- fast, convenient online submission

- thorough peer review by experienced researchers in your field

- rapid publication on acceptance

- support for research data, including large and complex data types

- gold Open Access which fosters wider collaboration and increased citations

- maximum visibility for your research: over $100 \mathrm{M}$ website views per year

At $\mathrm{BMC}$, research is always in progress.

Learn more biomedcentral.com/submission 